\title{
The Whole Price of Vancomycin: Toxicities, Troughs, and Time
}

\author{
Meghan N. Jeffres ${ }^{1}$
}

Published online: 1 June 2017

(c) The Author(s) 2017. This article is an open access publication

\begin{abstract}
Vancomycin is a glycopeptide antibiotic that is active against Gram-positive bacteria, including methicillin-resistant Staphylococcus aureus. Nephrotoxicity, which is usually reversible, is the most serious common adverse effect of vancomycin. Vancomycin-associated nephrotoxicity prolongs hospital stays, imposes a need for additional antibiotics and, in rare circumstances, dialysis treatment, and increases medical costs and mortality. Risk factors for nephrotoxicity include the dose and duration of vancomycin treatment, serum trough concentration, patient characteristics, and concomitant receipt of nephrotoxins. Contemporary guidelines recommend targeting vancomycin trough concentrations of $\geq 10 \mathrm{mg} / \mathrm{L}$ to prevent resistance and trough concentrations of $15-20 \mathrm{mg} / \mathrm{L}$ to optimize outcomes. There is significant correlation between vancomycin trough serum concentrations and the incidence of vancomycin-associated nephrotoxicity; however, evidence of an association between trough concentrations and efficacy is less convincing. Routine monitoring of serum vancomycin concentrations consumes time and limited healthcare resources and may not be cost effective. The use of alternative antibacterial agents that do not require monitoring would free up pharmacy resources. This time could then be devoted to initiatives such as pharmacist-led antibiotic stewardship programs that are known to reduce antibiotic use and promote improved patient outcomes.
\end{abstract}

Meghan N. Jeffres

Meghan.Jeffres@ucdenver.edu

1 Department of Clinical Pharmacy, Skaggs School of Pharmacy and Pharmaceutical Sciences, University of Colorado, 12850 E. Montview Blvd. V20-1212, Aurora, CO 80045, USA

\section{Key Points}

Vancomycin-associated nephrotoxicity is linked with increased duration of hospitalization, costs, and risk of mortality.

Elevated trough concentrations are associated with a higher incidence of nephrotoxicity, but not clinical cure.

Monitoring vancomycin concentrations consumes time and resources.

Use of alternative antibacterials could save time and resources that could then be devoted to initiatives like antibiotic stewardship, which has demonstrated improved patient outcomes.

\section{Introduction}

Vancomycin is a glycopeptide antibiotic that has been used since the mid-1950s to treat Gram-positive bacterial infections, including methicillin-resistant Staphylococcus aureus (MRSA) [1]. The Infectious Disease Society of America (IDSA) guidelines recommend vancomycin as a first-line agent for MRSA infections [2]. Furthermore, the guidelines for vancomycin therapeutic monitoring from the American Society of Health-System Pharmacists, IDSA, and the Society of Infectious Diseases Pharmacists suggest targeting vancomycin trough concentrations of $\geq 10 \mathrm{mg} / \mathrm{L}$ to avoid development of resistant strains [3] and trough concentrations of $15-20 \mathrm{mg} / \mathrm{L}$ to improve tissue penetration, increase the probability of achieving optimal target 
serum concentrations, and improve clinical outcomes. However, these recommendations were made with very little supporting clinical data and even less safety data [4]. Since the guidelines were published in 2009 , several studies have evaluated the efficacy and safety associated with more aggressive vancomycin dosing [5-8].

A limited number of studies have evaluated the time and money spent monitoring the efficacy and safety of vancomycin. While the average daily cost of vancomycin is relatively low (approximately \$US15-55) [9], a comprehensive account of the cost of vancomycin use would include the direct costs associated with measuring serum concentrations and those associated with the treatment of adverse reactions, namely nephrotoxicity. Monitoring serum concentrations involves the time of several health professionals to write orders, collect and process blood samples, report and interpret results, and document recommendations. The use of time for these purposes is associated with opportunity costs. Therefore, it may be useful to prescribe alternative antibiotics that do not require monitoring for MRSA infections, as this would free up time for clinicians, particularly pharmacists. This time could be devoted to initiatives with proven benefits, such as antibiotic stewardship programs.

The objective of this review was to describe the risk factors and consequences of vancomycin-associated nephrotoxicity, the value of monitoring serum vancomycin concentrations, and to discuss the direct and indirect costs associated with nephrotoxicity. Finally, we consider pharmacokinetic and clinical alternatives to vancomycin serum concentration monitoring, including stewardship programs, as a potential use for pharmacist time.

\section{Search Strategy and Criteria}

A "focused search" strategy was employed to retrieve relevant articles from the PubMed database. Search terms including "vancomycin", "nephrotoxicity", "acute kidney injury (AKI)", "AKI Network (AKIN)", and "serum concentration" were used to identify articles of interest. In addition, the reference lists of each cited article were searched manually to identify other articles of potential interest.

\section{Vancomycin-Associated Nephrotoxicity}

Nephrotoxicity is a significant adverse event associated with vancomycin that is reversible in most cases [10]. Vancomycin-associated nephrotoxicity has been generally defined as changes from baseline in serum creatinine ( $\mathrm{SCr}$ ) or creatinine clearance $(\mathrm{CrCl})$ [11]. AKI in clinical practice is often defined on the basis of the RIFLE (Risk, Injury, Failure, Loss of kidney function, and End-stage kidney disease) or AKIN criteria [12]; however, these systems have rarely been used to define vancomycin-associated nephrotoxicity or evaluate outcomes in such patients. The RIFLE criteria are used to grade kidney dysfunction as risk, injury, or failure based on the magnitude of the increase in $\mathrm{SCr}$ or decrease in urine output. Risk, injury, and failure are defined, respectively, as a 1.5-, 2-, or 3-fold increase in $\mathrm{SCr}$; a 25,50 , and $75 \%$ decrease in glomerular filtration rate (GFR); or a urine output $<0.5 \mathrm{ml} / \mathrm{kg} / \mathrm{h}$ for $6 \mathrm{~h}$, $<0.5 \mathrm{ml} / \mathrm{kg} / \mathrm{h}$ for $12 \mathrm{~h}$, or $<0.3 \mathrm{ml} / \mathrm{kg} / \mathrm{h}$ for $24 \mathrm{~h}[12,13]$. In addition to the 3 RIFLE risk levels, the outcome of AKI is graded as "loss" or "end-stage renal disease" when renal replacement therapy is required for $>4$ and $>12$ weeks.

The AKIN criteria include an absolute increase in $\mathrm{SCr}$ of $\geq 0.3 \mathrm{mg} / \mathrm{dl}, \mathrm{a} \geq 50 \%$ increase in $\mathrm{SCr}$ within $48 \mathrm{~h}$, or urine output $<0.5 \mathrm{ml} / \mathrm{kg} / \mathrm{h}$ for $\geq 6 \mathrm{~h}$ [14]. AKIN stages 1,2 , and 3 are defined as urine output $<0.5 \mathrm{ml} / \mathrm{kg} / \mathrm{h}$ for $6 \mathrm{~h}$ ( $\mathrm{SCr}$ of $\geq 1.5$ - to 2-fold from baseline), $<0.5 \mathrm{ml} / \mathrm{kg} / \mathrm{h}$ for $12 \mathrm{~h}$ ( $\mathrm{SCr}$ of $>2$ - to 3 -fold from baseline), or $<0.3 \mathrm{ml} / \mathrm{kg} / \mathrm{h}$ for $24 \mathrm{~h}$ (SCr of $>3$-fold from baseline), respectively [14]. Using the AKIN criteria may facilitate early identification of patients with vancomycin-associated nephrotoxicity according to the results of a prospective observational study [15]. In this study, 43 of 227 (19\%) patients were diagnosed with AKI per AKIN criteria with onset within 6 days of vancomycin therapy. In contrast, just 17 of these 43 patients had AKI according to the traditional criteria (increase in $\mathrm{SCr}$ of $\geq 0.5 \mathrm{mg} / \mathrm{dl}$ or $50 \%$ over baseline) [15]. Moreover, most of the patients identified by AKIN criteria were identified during AKI stage $1(92 \%)$ and were considered to be at risk of AKI (68\%), whereas most patients diagnosed by traditional criteria were identified during AKI stage $2(59 \%)$ and were considered to have already sustained injury (65\%). Earlier diagnosis of AKI using the AKIN criteria resulted in a trend towards a shorter median length of stay (7.5 vs. 11 days) and lower mortality rate (12 vs. $29 \%$ ) than when traditional criteria were used; however, these differences were not significant [15].

\subsection{Evidence for Vancomycin-Associated Nephrotoxicity}

Nephrotoxicity associated with vancomycin treatment has been reported by a number of studies. For example, Prabaker et al. [16], evaluated nephrotoxicity in 348 patients who had received $\geq 5$ days of vancomycin treatment. Vancomycin-associated nephrotoxicity was defined as a $50 \%$ increase in $\mathrm{SCr}$ on $\geq 2$ consecutive days after initiation of vancomycin treatment and for up to $72 \mathrm{~h}$ after the final dose. The overall incidence of nephrotoxicity was $8.9 \%$ (31/348), and resolution of nephrotoxicity was 
observed in $21 / 27$ patients $(77.8 \%)$ either prior to or within $72 \mathrm{~h}$ of vancomycin discontinuation (4 patients did not have a follow-up $\mathrm{SCr}$ determination within $72 \mathrm{~h}$ of discontinuing vancomycin therapy). The remaining 6 patients had all received treatment with concomitant nephrotoxins prior to the onset of nephrotoxicity [16]. An analysis conducted by the Spanish National Health System [17] evaluated healthcare resource utilization in hospitalized patients with nosocomial pneumonia treated with either linezolid or vancomycin. Renal failure was defined using RIFLE criteria, and 43 patients developed renal failure during the trial, including 34 recipients of vancomycin and 9 recipients of linezolid $(p<0.001)$ [17].

The clinical impact of vancomycin-associated nephrotoxicity can be challenging to determine because of different definitions of nephrotoxicity, difficulties related to assessing recovery, and limited data regarding the clinical outcomes of patients who develop nephrotoxicity. A number of meta-analyses have evaluated various factors that drive nephrotoxicity associated with vancomycin therapy. A meta-analysis of 15 studies using data from patients with vancomycin trough concentrations ( $<15$ vs. $\geq 15 \mathrm{mg} / \mathrm{L}$ ) showed that nephrotoxicity occurred on average 4-17 days after the start of vancomycin therapy, and that the incidence ranged from 5 to $43 \%$ with the wide variation reflecting the characteristics of the population, in particular residence in an intensive care unit (ICU) [11]. Renal function recovered within 1 week of vancomycin discontinuation in $44-75 \%$ of patients with nephrotoxicity [11]. Elyasi et al. [18], reviewed 81 total and 57 human studies and determined that vancomycin-associated nephrotoxicity was common in individuals with concomitant predisposing risk factors. Some of the well-studied risk factors included high trough vancomycin level (>20 mg/L) or doses ( $>4 \mathrm{~g} /$ day), treatment with concomitant nephrotoxic agents, prolonged therapy ( $>7$ days), and prolonged ICU stay. Vancomycin-associated nephrotoxicity was rare in patients without predisposing factors and for the most part was a reversible adverse effect [18]. Another review of 12 studies critically evaluated the risk of developing nephrotoxicity ( $\geq 50 \%$ increase over baseline $\mathrm{SCr}$ or a $50 \%$ decrease in $\mathrm{CrCl}$ from baseline) with high-dose vancomycin treatment (daily dose $\geq 4 \mathrm{~g}$ or $>30 \mathrm{mg} / \mathrm{kg}$ or trough concentrations of $15-20 \mathrm{mg} / \mathrm{L})$. This analysis determined that high-dose vancomycin therapy was associated with higher nephrotoxicity, especially when risk factors, such as prolonged therapy ( $>7$ days), receipt of concomitant nephrotoxins or vasopressors, and physical impairment (e.g., obesity), were included [19]. A metaanalysis of 7 studies evaluated the effect of continuous vs. intermittent vancomycin infusion on the development of nephrotoxicity. This analysis determined that continuous infusion of vancomycin was associated with a lower risk of nephrotoxicity compared with intermittent infusion; however, this trend was not significant, and further study is needed to ascertain the benefits of either infusion type [20].

Combinations of vancomycin and other antibacterial agents are increasingly being used to treat serious MRSA infections [21]. In a recent study, combinations of vancomycin and $\beta$-lactams resulted in significantly higher microbiological eradication of MRSA bacteremia than vancomycin alone (96 vs. $80 \% ; p=0.021$ ) [22]. However, several studies have reported an increased incidence of nephrotoxicity with a vancomycin plus piperacillin-tazobactam (PTZ) combination [23-25]. A large retrospective cohort $(N=11650)$ was evaluated to determine the AKI incidence in patients treated with vancomycin or PTZ alone or in combination. The AKI incidence was determined to be significantly higher in the vancomycin-PTZ group $(21 \%)$ than either of vancomycin $(8.3 \%)$ or PTZ $(7.8 \%)$ treatment groups $(p<0.0001)$ [24]. Another study sought to determine whether the addition of PTZ in patients receiving vancomycin treatment increased nephrotoxicity and found a higher incidence of nephrotoxicity in the combination group than in the vancomycin group (16.30 vs. $8.08 \% ; p=0.041$ ) [25]. A separate retrospective analysis compared AKI between patients treated with vancomycin-PTZ and those treated with vancomycin-cefepime and found a significantly higher AKI incidence in the vancomycin-PTZ group than in the vancomycin-cefepime group (34.8 vs. $12.5 \% ; p<0.0001)$ [23]. These data suggest that a vancomycin-PTZ combination may be associated with an increased risk of nephrotoxicity, and therefore, warrants judicious use in empiric therapy. The mechanism of this increase in nephrotoxicity following combined treatment with vancomycin and PTZ needs to be further characterized by randomized controlled trials.

\section{Risk Factors for Vancomycin-Associated Nephrotoxicity}

The dose and duration of vancomycin therapy and the serum trough concentration are all predictors of vancomycin-associated nephrotoxicity. In a retrospective cohort study $(N=291)$, patients with Gram-positive infections who received a vancomycin dose $\geq 4 \mathrm{~g}$ /day were 4.4 times more likely $(p=0.003)$ to develop nephrotoxicity (increase in $\mathrm{SCr}$ of $0.5 \mathrm{mg} / \mathrm{dL}$ or $50 \%$ over baseline) than those who received lower vancomycin doses [26]. According to the meta-analysis by van Hal et al. [11], vancomycin trough concentrations $\geq 15 \mathrm{mg} / \mathrm{L}$ were associated with higher odds of nephrotoxicity than troughs $<15 \mathrm{mg} / \mathrm{L}$ (odds ratio [OR] 2.67; 95\% confidence interval [CI] 1.95-3.65). In addition, there was an incremental increase in the risk of nephrotoxicity with longer durations 
of treatment (i.e., 7-14 days compared with $<7$ days; $p=0.004$ ) [27].

Patient factors and treatment with concomitant nephrotoxic medications also increase the risk of vancomycin-associated nephrotoxicity. Well-established patient risk factors for nephrotoxicity include greater patient weight [26, 28], pre-existing renal impairment [7, 15], and longer duration of stay in an ICU $[15,26,28]$. Figure 1 contains the design details and results of 4 studies that have evaluated risk factors associated with vancomycin-associated nephrotoxicity. Lodise et al. [26] reported that, in addition to high doses of vancomycin, body weight $\geq 101.4 \mathrm{~kg}, \mathrm{CrCl} \leq 86.6 \mathrm{ml} /$ min, and residence in an ICU were significantly associated with nephrotoxicity in their multivariate analysis. Coadministration of nephrotoxic medications increases the risk of nephrotoxicity and is perhaps most often reported with aminoglycoside antibiotics [27, 29, 30]. A multivariate analysis of data from 188 patients with hospital-acquired pneumonia showed that serum vancomycin trough concentrations $\geq 15 \mathrm{mg} / \mathrm{L}$ (OR 5.2; $95 \%$ CI 1.9-13.9), longer duration of vancomycin therapy (OR 1.12 per additional treatment day; 95\% CI 1.02-1.23), and concomitant treatment with an aminoglycoside (OR 2.67; 95\% CI 1.09-6.54) were all significantly associated with nephrotoxicity [30]. An analysis of data from patients with and without nephrotoxicity after $\geq 5$ days of treatment with vancomycin showed that significantly more patients ( $p=0.03$ ) with nephrotoxicity had received concomitant nephrotoxic agents, including aminoglycoside antibiotics, intravenous contrast agents, nonsteroidal anti-inflammatory drugs, loop diuretics, and angiotensinconverting enzyme inhibitors [15].

As noted, renal function recovers in most patients with vancomycin-associated nephrotoxicity after withdrawal of vancomycin. However, patients with nephrotoxicity tend to have worse outcomes than those whose renal function is minimally changed during treatment with vancomycin. Data show that patients with nephrotoxicity have prolonged hospital stays, are more likely to require treatment with additional antibiotics and/or dialysis, have higher healthcare costs, and are associated with higher mortality rates than patients without nephrotoxicity [15, 31-33].

\section{Consequences of Nephrotoxicity}

Even modest increases in SCr have been correlated with increased medical costs, length of stay, and mortality in hospitalized patients [34]. This section reviews studies that explore some of these themes. It is important to understand that these studies are observational or retrospective in
Fig. 1 Risk factors for vancomycin-associated nephrotoxicity. Abrupt (within $48 \mathrm{~h}$ ) reduction in kidney function signified by an absolute increase in $\mathrm{SCr}$ of $\geq 0.3 \mathrm{mg} / \mathrm{L}$, an increase in $\mathrm{SCr}$. $A K I$ acute kidney injury, $A K I N$ acute kidney injury network, $A M G$ aminoglycoside, APACHE II Acute Physiology and Chronic Health Evaluation II, $B U N: S C r>20$ ratio of blood urea nitrogen to serum creatinine $>20, \mathrm{CrCl}$ creatinine clearance, $\mathrm{HAP}$ hospital-acquired pneumonia, $H C A P$ healthcare-associated pneumonia, $I C U$ intensive care unit, $I V$ intravenous, $L O S$ length of stay, $N R$ not reported, $S C r$ serum creatinine, $\operatorname{tr}$ trough, $V A N$ vancomycin-associated nephrotoxicity, $V A P$ ventilator-associated pneumonia. ${ }^{1}$ In addition, data from 45 patients who received linezolid were included as a control group. Data from this group are not included in the table. ${ }^{2}$ Mortality at 28 days; $p=0.48$. ${ }^{3}$ Median LOS; $p=0.06$. ${ }^{4}$ Continuous variable (per day)

nature and, therefore, it is difficult to prove direct causality between vancomycin-associated nephrotoxicity and the consequences of increased costs, stay, or patient mortality.

\subsection{Increased Length of Stay}

A number of studies have demonstrated that nephrotoxicity is associated with increased hospitalization. In a retrospective cohort study of patients with MRSA bacteremia who received vancomycin, the duration of hospitalization was reported to be significantly longer in patients with nephrotoxicity than in those without nephrotoxicity (20 vs. 13 days; $p=0.001$ ) [29]. Another study of 94 patients with healthcare-associated MRSA pneumonia who received vancomycin showed that the length of hospital stay was significantly longer in patients who developed nephrotoxicity than in those without nephrotoxicity $(44.8$ vs. 28.7 days, respectively; $p=0.006$ ) [31]. Consistent with these results, another retrospective analysis of 188 patients with pneumonia who received vancomycin in an ICU showed that patients with nephrotoxicity remained in the ICU for significantly longer than those without nephrotoxicity (median 17 vs. 12 days, respectively; $p=0.03$ ) [30]. The total duration of hospitalization was also longer, although the difference between patients with and without nephrotoxicity was not statistically significant (median 20 vs. 15 days; $p=0.06$ ). Similar findings were noted in a retrospective review of patients $(N=227)$ in a tertiary care center in South Carolina, wherein patients treated with linezolid had a significantly higher probability of being discharged than vancomycin-treated patients [35]. Furthermore, an analysis conducted from the Spanish National Health System concluded that, in patients with renal failure, recipients of vancomycin spent more days on mechanical ventilation (13.2 vs. 7.6 days), in the ICU (14.4 vs. 9.9 days), and in hospital (19.5 vs. 16.1 days) than recipients of linezolid, although the differences were not statistically significant [17]. Taken together, these studies demonstrate a clear relationship between nephrotoxicity 
A

\begin{tabular}{|c|c|c|c|c|}
\hline Citation & $\begin{array}{l}\text { Jeffres et al. } \\
2007\end{array}$ & $\begin{array}{l}\text { Lodise et al. } \\
2008\end{array}$ & $\begin{array}{l}\text { Minejima et al. } \\
2011\end{array}$ & $\begin{array}{l}\text { Cano et al. } \\
2012\end{array}$ \\
\hline Study design & $\begin{array}{l}\text { Retrospective cohort, } \\
\text { single-center, } \\
\text { observational }\end{array}$ & $\begin{array}{l}\text { Retrospective cohort, } \\
\text { observational }\end{array}$ & $\begin{array}{l}\text { Prospective cohort, } \\
\text { observational }\end{array}$ & $\begin{array}{l}\text { Retrospective, } \\
\text { multicenter, } \\
\text { observational }\end{array}$ \\
\hline Patients (N) & 94 & $\begin{array}{l}246^{1}(\geq 4 \text { vs }<4 \mathrm{~g} / \\
\text { day: } \mathrm{n}=26 \text { and } 220)\end{array}$ & 227 & 188 \\
\hline Disease state & HCAP & Various & Various & HAP, VAP, and HCAP \\
\hline $\begin{array}{l}\text { Definition of } \\
\text { nephrotoxicity }\end{array}$ & $\begin{array}{l}0.5 \mathrm{mg} / \mathrm{dL} \text { increase } \\
\text { in } \mathrm{SCr} \text { or } \geq 50 \% \\
\text { increase from } \\
\text { baseline } \mathrm{SCr}\end{array}$ & $\begin{array}{l}\text { SCr increase } \\
\geq 0.5 \mathrm{mg} / \mathrm{dL} \\
\text { or } \geq 50 \%\end{array}$ & AKIN criteria ${ }^{4}$ & $\begin{array}{l}\mathrm{SCr} \text { increase } \geq 0.5 \\
\mathrm{mg} / \mathrm{dL} \text { or } \geq 50 \% \\
\leq 72 \text { hrs post- } \\
\text { treatment }\end{array}$ \\
\hline $\begin{array}{l}\text { VAN incidence, } \\
\text { n (\%) }\end{array}$ & $40(42.6 \%)$ & $\begin{array}{l}\geq 4 \text { vs }<4 \mathrm{~g} / \\
\text { day: } 34.6 \% \text { vs } \\
10.9 \%\end{array}$ & $\begin{array}{l}43(18.9 \%) \\
>15 \text { vs }<15 \mathrm{mg} / \mathrm{L} \\
(24 \% \text { vs } 17 \%)\end{array}$ & $29(15.4 \%)$ \\
\hline Mortality & $27.7 \%$ (in-hospital) & NR & $\begin{array}{l}\text { AKI vs no AKI } \\
\text { ( } 28 \text {-day mortality): } \\
29 \% \text { vs } 12 \%\end{array}$ & $\begin{array}{l}\text { VAN vs no VAN } \\
\text { ( } 28-\text {-day mortality): } \\
33.3 \% \text { vs } 25.3 \%^{2}\end{array}$ \\
\hline Mean LOS & 35.6 days & NR & $\begin{array}{l}\text { AKI vs no AKI: } \\
11 \text { vs } 8 \text { days }\end{array}$ & $\begin{array}{l}\text { VAN vs no VAN: } \\
20 \text { vs } 15 \text { days }^{3}\end{array}$ \\
\hline
\end{tabular}

B

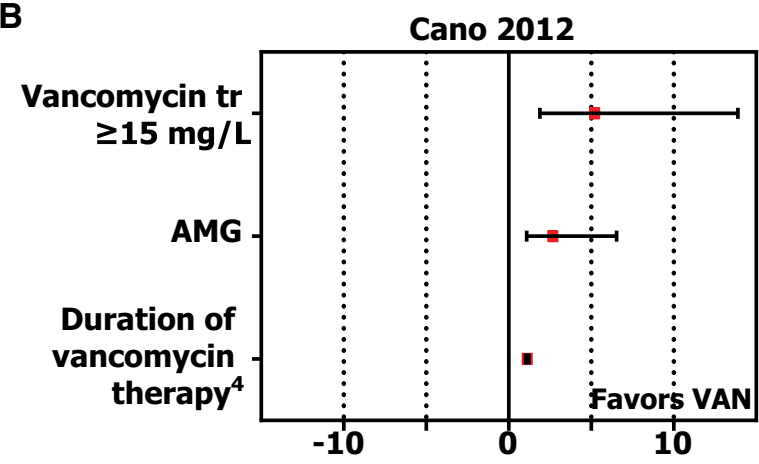

D

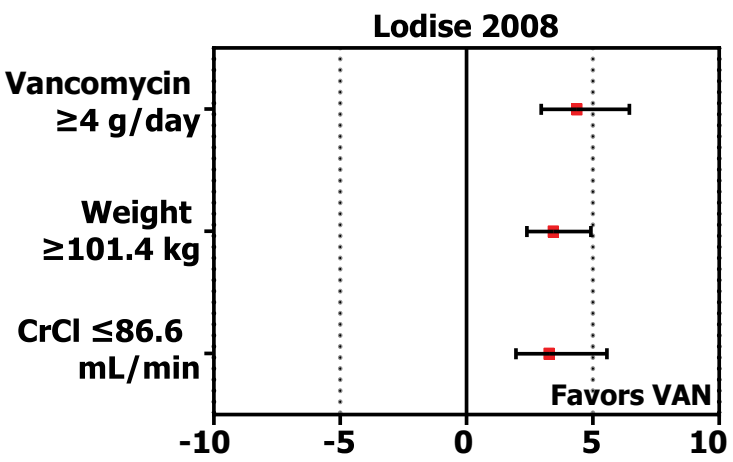

C

Minejima 2011

Prior episode of AKI

Vancomycin $x>7$ days

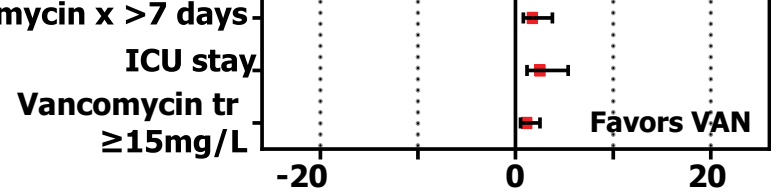

E

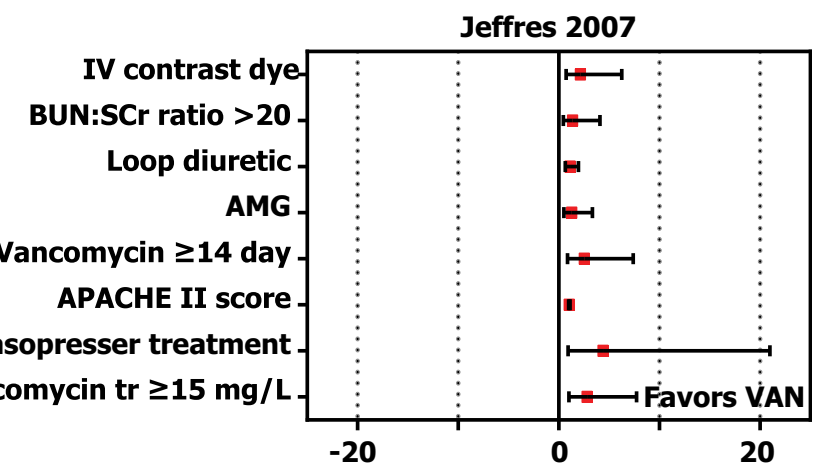


induced by vancomycin treatment and increased length of hospital stay.

\subsection{Need for Dialysis}

While uncommon, vancomycin-associated nephrotoxicity can progress to acute renal failure requiring dialysis [36]. A meta-analysis by van $\mathrm{Hal}$ et al. [11] included 15 vancomycin-associated nephrotoxicity studies. In a subset of studies that reported on the clinical course of vancomycinassociated nephrotoxicity, short-term dialysis was required for 6 of $192(3 \%)$ patients. A retrospective study published after the meta-analysis compared rates of nephrotoxicity and renal failure requiring dialysis between critically ill patients treated with vancomycin $(n=571)$ or linezolid $(n=475)$ [37]. This study found that vancomycin trough levels $>20 \mathrm{mg} / \mathrm{L}$ correlated with a significantly elevated risk for creatinine increase (relative risk [RR] 5.4; 95\% CI 1.19-24.51) [37]. However, no significant differences were observed between the 2 treatment groups and the rate of hemodialysis (vancomycin 9.4\% vs. linezolid 9.7\%) [37]. Overall, these reports suggest that in the majority of cases only a small percentage of patients with nephrotoxicity require dialysis, and further study is needed to identify predictors of vancomycin-associated nephrotoxicity resulting in the need for dialysis in patients with renal failure.

\subsection{Increased Mortality}

Causation between vancomycin-associated nephrotoxicity and mortality has not been established. However, a correlation between vancomycin-associated nephrotoxicity and mortality has been reported in patients with severe Grampositive infections [15, 31-33, 35]. A retrospective analysis of 337 patients with MRSA bacteremia who received vancomycin evaluated the differences in effectiveness of guideline-recommended vs. lower-dose treatment. This analysis identified nephrotoxicity as an independent risk factor for in-hospital mortality that was not related to vancomycin dosing [33]. Other significant predictors associated with mortality included ICU admission, Pitt bacteremia score $\geq 4$, and age of $\geq 53$ years. In another retrospective study of 94 patients with healthcare-associated MRSA pneumonia who received vancomycin, inhospital mortality rates were also significantly higher in patients with nephrotoxicity than without (45 vs. $15 \%$, respectively; $p=0.001$ ) [31]. Similar increased patient mortality was also noted in a tertiary and quaternary medical center, wherein patients treated with vancomycin had a higher mortality rate than linezolid-treated patients (19.5 vs. $10 \% ; p=0.046$ ) [35]. Among 227 patients who received vancomycin for $\geq 5$ days at a community teaching hospital, 43 individuals (19\%) developed nephrotoxicity. The 28-day mortality rate was $16 \%(7 / 43)$ in patients with nephrotoxicity and 5\% (9/184) in those without AKI $(p<0.05)$ [15]. The baseline characteristics of patients with and without nephrotoxicity were similar, with the exception of a lower GFR, higher Acute Physiology and Chronic Health Evaluation II scores, and a higher prevalence of malignancies among those with nephrotoxicity. These data indicate a strong connection between vancomycin-associated nephrotoxicity and higher patient mortality rates. However, further study is needed to determine whether nephrotoxicity induced by vancomycin treatment plays a more causal role in driving patient mortality.

\subsection{Increased Costs}

Vancomycin-associated nephrotoxicity is linked with increased direct medical costs. Economic analyses of data from 448 patients enrolled in the randomized ZEPHyR trial [38] showed that medical costs were considerably higher in patients with nosocomial MRSA pneumonia who developed nephrotoxicity during treatment with vancomycin or linezolid [17, 39]. Overall healthcare resource use and costs were similar in patients randomized to vancomycin or linezolid in the study. However, total treatment costs $(p=0.046)$ were significantly higher (by approximately \$US8000) in patients with renal failure, and the incidence of renal failure was significantly higher in patients randomized to vancomycin than in those receiving linezolid (15 vs. $4 \%$, respectively; $p<0.001)$ [39]. Total costs in patients with renal failure were slightly higher in recipients of vancomycin than in those receiving linezolid (\$US54415 vs. \$US44054; $p=0.47$ ) [39]. This finding was also noted in another retrospective review $(N=227)$, wherein patients treated with linezolid incurred slightly lower median total hospital charges (\$US25900 vs. $\$ U S 32100 ; p=0.311$ ) [35]. A Spanish National Health System study concluded that, in patients with renal failure, total medical costs were numerically higher for recipients of vancomycin than for recipients of linezolid (€20263 vs. $€ 17219 ; p=0.51$ ) [17]. A total of 43 patients developed renal failure during the trial, including 34 recipients of vancomycin and 9 recipients of linezolid $(p<0.001)$.

The increase in total medical costs is notable since the antibacterial acquisition cost for vancomycin is much lower than for other anti-MRSA antibiotics. The daily cost of vancomycin ranges from \$US15 to \$US55 compared with daptomycin at \$US450 to \$US750 per day, ceftaroline at \$US370 to \$US550 per day, linezolid at \$US190 to \$US370 per day, or telavancin at \$US430 per day [9]. These studies highlight that the increased safety and efficacy of an antibacterial is likely worth the higher 
acquisition costs. The large disparity in cost between antiMRSA antibacterials will dwindle because of the recent expiration of patents for daptomycin [40, 41] and linezolid [42]. The lower cost for generic antibacterial agents will change pharmacoeconomic models and likely result in a shift from vancomycin being the empiric anti-MRSA antibacterial of choice.

\section{Pharmacokinetic/Pharmacodynamic Factors}

\subsection{Vancomycin Troughs}

Consensus guidelines recommend serum vancomycin trough concentrations of $15-20 \mathrm{mg} / \mathrm{L}$ in adults with complicated $S$. aureus infections [3]. Achievement of a target vancomycin trough concentration of $15-20 \mathrm{mg} / \mathrm{L}$ has been associated with greater efficacy in patients with MRSA [27], and troughs $>15 \mathrm{mg} / \mathrm{L}$ have also been associated with an increased likelihood of nephrotoxicity in both prospective [8, 27, 43] and retrospective studies [7, 29, 31]. This evidence indicates that the guidelines may overemphasize the value of monitoring vancomycin trough concentrations to predict nephrotoxicity.

There are several limitations in using vancomycin troughs to optimize vancomycin dosing [3]. A vancomycin trough concentration represents a single exposure point at the end of a single dosing interval, and is, therefore, unlikely to accurately portray or predict the entire concentration-time profile throughout a course of therapy [44]. A series of simulations that calculated the probability of achieving a target area under the concentration-time curve (AUC) to minimum inhibitory concentration (MIC) ratio (AUC/MIC) of $\geq 400$, and of developing nephrotoxicity, found high degrees of inter- and intra-individual variability in vancomycin trough concentrations when vancomycin dose, ICU residence, and $\mathrm{CrCl}$ were considered [44]. Although trough concentrations of $15-20 \mathrm{mg} / \mathrm{L}$ were closely linked to nephrotoxicity in these simulations, they did not consistently result in optimal AUC/MIC ratios, especially when the MIC for the infecting organism was assumed to be $2 \mathrm{mg} / \mathrm{L}$. The focus on achieving this optimal AUC/MIC ratio has primarily been for MRSA [45] and not other pathogens where different pharmacodynamic goals may need to be defined.

Although a significant correlation between elevated vancomycin trough concentrations and nephrotoxicity has been found [11], the correlation between vancomycin trough concentrations and patient outcomes is not strong. For example, in the prospective ZEPHyR trial in patients with MRSA nosocomial pneumonia, the incidence of renal toxicity increased progressively with vancomycin trough and was 18,22 , and $37 \%$ in those with troughs of $<15$,
$15-20$, and $\geq 20 \mathrm{mg} / \mathrm{L}$, respectively. However, the treatment outcome in these patients was similar regardless of the day 3 vancomycin trough concentration when analyzed by quartile [38].

Consistent with these results, Jeffres et al. [46], found that vancomycin trough concentrations $(p=0.866)$ and AUC values $(p=0.941)$ were similar in patients who did and did not die during treatment for MRSA nosocomial pneumonia. Of 102 patients included in the retrospective analysis, 32 died and the mean serum trough concentrations in survivors and nonsurvivors were 13.6 and $13.9 \mathrm{mg} / \mathrm{L}$, respectively. When all patients included in the analysis were grouped according to high $(\geq 15 \mathrm{mg} / \mathrm{L})$ and low $(<15 \mathrm{mg} / \mathrm{L})$ vancomycin trough concentrations, the difference in mortality rates was not statistically significant (35.3 vs. $29.4 \% ; p=0.546$ ). The authors concluded that aggressive dosing strategies that target trough concentrations $>15 \mathrm{mg} / \mathrm{L}$ may not offer advantages over more conservative dosing regimens [46].

In contrast, a retrospective single-center study that compared outcomes before and after implementation of guidelines recommending a target vancomycin trough concentration of $15-20 \mathrm{mg} / \mathrm{L}$ showed that, although success rates for patients with complicated MRSA bacteremia improved significantly $(p=0.034)$, there was no statistically significant difference in the mean length of stay $(p=0.28)$ or in the incidence of nephrotoxicity $(p=0.85)$ between the 2 study periods [6]. Initial serum vancomycin concentrations were significantly lower before than after the implementation of the new guidelines $(12.3 \mathrm{mg} / \mathrm{L}$ in $2005-07$ vs. $15.8 \mathrm{mg} / \mathrm{L}$ in $2008-10 ; p=0.02$ ).

\subsection{Vancomycin Area Under the Curve to Minimum Inhibitory Concentration Ratio}

The AUC/MIC ratio has been proposed as an alternative to serum trough concentration for monitoring the efficacy of vancomycin. In the case of $S$. aureus, a vancomycin AUC/ MIC ratio $\geq 400$ has been suggested to provide a bactericidal effect that is superior to lower values [4]. This is based on a retrospective analysis of data from 108 patients with lower respiratory tract infections, among whom an AUC/MIC value of at least 350 was associated with superior clinical and bacteriological outcomes, whereas lower values were associated with a significantly lower clinical success rate (OR 7.19; $p=0.0036$ ) [47]. On the basis of this study, the 2009 vancomycin consensus guidelines included a recommendation that a target AUC/ MIC ratio $\geq 400$ should be achievable in patients with serum trough concentrations of $15-20 \mathrm{mg} / \mathrm{L}$, provided that the MIC of the infecting pathogen is $\leq 1 \mathrm{mg} / \mathrm{L}$ [3]. However, a target AUC/MIC $\geq 400$ is difficult to achieve with conventional dosing in patients with normal renal function 
if the MIC is $\geq 2 \mathrm{mg} / \mathrm{L}$. According to simulations performed by Patel et al. [44], if the infecting pathogen has an MIC of $2 \mathrm{mg} / \mathrm{L}$, the use of an aggressive dosing regimen $(2 \mathrm{~g}$ every $12 \mathrm{~h})$ would result in attainment of the target AUC/MIC of $\geq 400$ in only $57 \%$ of patients while precipitating nephrotoxicity in $34 \%$ of patients.

The efficacy and safety of achieving and maintaining an AUC/MIC $\geq 400$ has not been evaluated in prospective randomized clinical studies. However, a meta-analysis of 9 cohort studies has compared clinical outcomes in patients with high and low AUC/MIC ratios $(\geq 400$ and $<400)$. Patients with high AUC/MICs had significantly lower mortality rates (RR 0.47 ; 95\% CI: $0.31-0.70 ; p<0.001$ ) and treatment failure rates (RR 0.47 ; $95 \%$ CI $0.30-0.73$; $p=0.001)$ than patients with low AUC/MICs [48].

Higher steady state AUCs for vancomycin have also been shown to be associated with nephrotoxicity. Patients with AUCs $\geq 1300 \mathrm{mg} \cdot \mathrm{h} / \mathrm{L}$ had a significantly higher incidence of nephrotoxicity ( 25.9 vs. $10.1 \%$; $p=0.05$ with lower exposure) in a retrospective analysis of data from 166 patients who received vancomycin for $\geq 48 \mathrm{~h}$ [28]. This trial also confirmed that trough concentrations were associated with nephrotoxicity; patients with an initial trough concentration of $\geq 9.9 \mathrm{mg} / \mathrm{L}$ had a significantly higher incidence of nephrotoxicity than patients with lower exposure (22 vs. $5 \% ; p=0.001$ ) [28].

Practical limitations mitigate against using the AUC/ MIC ratio to optimize vancomycin dosing. Simulations conducted by Neely et al. [49], using pooled data from 47 adult patients who underwent intensive sampling in 3 studies, showed that estimating the AUC using a trough value alone significantly underestimated the "true" AUC by $25 \%$ [49]. Moreover, serum trough concentrations vary greatly among patients with normal renal function receiving identical dosing regimens. Neely et al. [49], estimated that at least $50 \%$ of patients with a true AUC of $\geq 400 \mathrm{mg} \cdot \mathrm{h} / \mathrm{L}$, the target for infections with MIC values of $1 \mathrm{mg} / \mathrm{L}$, would not have a trough serum concentration $>15 \mathrm{mg} / \mathrm{L}$. Thus, adjusting the dose upward to achieve a target trough concentration of $15 \mathrm{mg} / \mathrm{L}$ would needlessly increase the risk of nephrotoxicity in this large subset of patients. As noted, it is difficult to achieve a target AUC/ MIC $\geq 400$ for patients in whom the infecting organism has an $\mathrm{MIC}$ of $\geq 1 \mathrm{mg} / \mathrm{L}$ with a standard dosing regimen $[26,47]$.

\section{Alternatives to Vancomycin}

Vancomycin is considered the gold standard for treatment of MRSA infections [50]. However, in addition to nephrotoxicity, several issues, including slow bactericidal activity, low tissue penetration, and increasing reports of resistance and failure, restrict its usefulness [28, 29, 51]. A number of antibacterial agents, including daptomycin, linezolid, ceftaroline, and telavancin, have demonstrated efficacy in treating various MRSA infections [9, 50]. However, a limited number of studies have evaluated druginduced nephrotoxicity as an outcome. Table 1 summarizes studies that have assessed the incidence of nephrotoxicity following treatment with vancomycin or an alternative agent. In 2 of the 3 studies, vancomycin treatment was associated with a higher rate of nephrotoxicity and poorer clinical outcomes than alternative agents [38, 52]. Carreno et al. [53], conducted a prospective randomized controlled trial to determine whether an early switch to an alternative therapy (daptomycin, linezolid, or ceftaroline) would prevent AKI in high-risk patients treated with vancomycin. Surprisingly, their analyses did not find a significant difference in the incidence of nephrotoxicity between patients treated with vancomycin or an alternative agent [53]. This finding is unexpected given the common belief that vancomycin treatment is associated with an increased risk for nephrotoxicity or AKI. Therefore, it will be important in the future to evaluate nephrotoxicity as an outcome to better characterize the utility and safety of an alternative therapy.

\section{Provider Time and Associated Costs}

Monitoring vancomycin serum concentrations and adjusting doses uses pharmacists' time and incurs costs. A retrospective analysis of the cost effectiveness of pharmacist-initiated vancomycin dose adjustments to prevent nephrotoxicity found that pharmacists spend about 40 min per patient reviewing charts, performing pharmacokinetic calculations, interpreting results, and following up with patients. The study included data from 57 patients receiving concomitant nephrotoxins, 68 in an ICU, and 78 with malignancies. The mean cost of preventing nephrotoxicity through pharmacokinetic dose adjustments was estimated to be $\$$ US25,167 per episode, and the mean cost of treating a nephrotoxic episode was \$US11,234. Patients requiring dose adjustments incurred additional costs due to laboratory assays, pharmacist time, and nursing time, in addition to the cost of treating nephrotoxicity [54]. The authors concluded that dose adjustments were not cost effective for all patients but were cost effective for patients receiving concomitant nephrotoxic medications and for patients in the ICU [54]. It must be noted that, as this study was conducted over 10 years ago, some of the numbers may not accurately reflect current drug costs.

In patients with uncomplicated MRSA bacteremia who received vancomycin for $\geq 72 \mathrm{~h}$, maintenance of more 
Table 1 Comparison of nephrotoxicity rates between vancomycin and alternative antibacterials

\begin{tabular}{|c|c|c|c|}
\hline Citation & Wunderink et al. [38] & Moise et al. [52] & Carreno et al. [53] \\
\hline Study design & $\begin{array}{l}\text { Phase IV, randomized, double-blind, multicenter, } \\
\text { comparator-controlled study }\end{array}$ & $\begin{array}{l}\text { Multicenter, retrospective } \\
\text { matched cohort study }\end{array}$ & Prospective RCT \\
\hline Patients $(N)$ & 1184 & 170 & 103 \\
\hline Disease state & MRSA, HAP, or HCAP & MRSA bacteremia & Various \\
\hline Treatment & IV VAN $15 \mathrm{mg} / \mathrm{kg} \mathrm{q} 12 \mathrm{~h}$ or LIN $600 \mathrm{mg} \mathrm{q} 12 \mathrm{~h}$ & $\begin{array}{l}\text { VAN } \operatorname{tr} \geq 10 \mathrm{mg} / \mathrm{L} \text { or DAP } \\
\geq 6 \mathrm{mg} / \mathrm{kg}\end{array}$ & $\begin{array}{l}\text { VAN or alternative agents } \\
(\mathrm{DAP}, \mathrm{LIN}, \text { or CEF) }\end{array}$ \\
\hline $\begin{array}{l}\text { Definition of } \\
\text { nephrotoxicity }\end{array}$ & $\begin{array}{l}0.5 \mathrm{mg} / \mathrm{ml} \text { increase in } \mathrm{SCr} \text { or } 50 \% \text { increase from } \\
\text { baseline SCr }\end{array}$ & $\begin{array}{l}0.5 \mathrm{mg} / \mathrm{dl} \text { or } 50 \% \text { increase in } \\
\mathrm{SCr}\end{array}$ & $\begin{array}{l}0.5 \mathrm{mg} / \mathrm{dl} \text { or } 50 \% \text { increase in } \\
\mathrm{SCr}\end{array}$ \\
\hline Efficacy outcomes & $\begin{array}{l}\text { VAN vs. LIN (clinical cure) }{ }^{\text {b,c }}: 44.9 \text { vs. } 54.8 \% \\
(\text { EOS); } 67.8 \text { vs. } 80.1 \% \text { (EOT) }\end{array}$ & $\begin{array}{l}\text { VAN vs. DAP (EOT failure): } \\
24 \text { vs. } 11 \%\end{array}$ & NR \\
\hline $\begin{array}{l}\text { Incidence of } \\
\text { nephrotoxicity, } \\
n(\%)\end{array}$ & VAN vs. LIN: 18.2 vs. $8.4 \%^{\mathrm{b}}$ & VAN vs. DAP: 23 vs. $9 \%^{\mathrm{c}}$ & $\begin{array}{l}\text { VAN vs. alternative agents: } 9.8 \\
\text { vs. } 6.1 \%^{\mathrm{d}}\end{array}$ \\
\hline
\end{tabular}

$C E F$ ceftaroline, DAP daptomycin, EOS end of study, EOT end of therapy, HAP hospital-acquired pneumonia, $H C A P$ healthcare-associated pneumonia, IV intravenous, LIN linezolid, MRSA methicillin-resistant Staphylococcus aureus, NR not reported, q12 h every 12 hours, RCT randomized controlled trial, $S C r$ serum creatinine, $\operatorname{tr}$ trough, $V A N$ vancomycin

${ }^{a}$ All study drugs were dosed per institutional renal dosing and pharmacokinetic protocols

${ }^{\mathrm{b}}$ Results are for the modified intent-to-treat population

c $p<0.05$

d Not significant

narrow vancomycin trough ranges (15-20 vs. $5-20 \mathrm{mg} / \mathrm{ml})$ significantly lowered median duration of vancomycin therapy (8.5 vs. 13 days, $p<0.001)$ with a slight but nonsignificant decrease in overall costs [6]. Total medication costs ( $\$$ US161.2 vs. $\$$ US116.48; $p=0.003$ ) and costs associated with monitoring vancomycin concentrations (\$US68.68 vs. \$US56.56; $p=0.004$ ) were higher after implementing more stringent target vancomycin concentrations. Length of stay was significantly longer in patients with nephrotoxicity (17 days [interquartile range (IQR) $11.5-36.5$ ] vs. 14 days [IQR 9-24]; $p=0.017$ ), and costs associated with monitoring renal function and vancomycin concentrations were increased in patients with nephrotoxicity; however, there was no statistically significant difference in the incidence of nephrotoxicity for the 2 target ranges [6].

\subsection{Redistribution of Effort}

Pharmacists can redistribute their time to antimicrobial stewardship program (ASPs) initiatives. For example, pharmacist-directed ASPs have been found to lower healthcare spending and improve patient outcomes [55]. Some ASPs have assessed the effect of antibacterial restriction on institutional expenditure, antibiotic usage and resistance, and patient outcomes [56, 57]. A restriction of ciprofloxacin at a tertiary care center was linked to a decrease in the resistance of Pseudomonas aeruginosa [57]. Another study evaluated a large cohort over a 5-year period and found that carbapenem restriction resulted in significantly lower antibacterial usage and incidence of resistance among $P$. aeruginosa isolates [56]. Furthermore, other ASPs instituted prior authorization or approval systems as a method of antibacterial restriction and observed improved antibacterial susceptibility, patient outcomes, and lower expenditures [58, 59]. White et al. [59] observed that instituting a prior authorization system dramatically lowered total expenditures by $32 \% \quad(p<0.01)$ and enhanced susceptibility to several antibacterial agents [59]. Implementation of an electronic approval system by a tertiary care hospital resulted in lower antibacterial consumption and a trend of increased $S$. aureus and $P$. aeruginosa susceptibility [58]. These data indicate that restricting antibacterials not only helps lower their overall usage but also improves antimicrobial susceptibility patterns. Antimicrobial stewardship programs aim to achieve optimal clinical outcomes from antimicrobial use while minimizing toxicity and other adverse events, thereby limiting the selective pressure that promotes antimicrobialresistant strain emergence [60]. It is recommended that the ASP team comprise a physician, a pharmacist, a clinical microbiologist, and an infection preventionist [60]. In institutions that do not have infectious disease (ID) physicians, more responsibility tends to be assumed by pharmacists.

An analysis of data before and after implementation of a pharmacist-driven ASP in such a hospital documented considerable cost savings [61]. After implementation of the ASP, the days of therapy per 1000 patient days decreased for carbapenems, daptomycin, echinocandins, and 
levofloxacin; increased for PTZ; and remained stable for linezolid and vancomycin. In addition, a statistically significant reduction in the mean length of stay in patients with a diagnosis of community-acquired pneumonia coincided with the implementation of the ASP (3.4 vs. 2.7 days; $p=0.03$ ). Perhaps most impressive was the $58 \%$ reduction in antibiotic expenditures, from \$US1.3 million to \$US0.75 million. The program was well received, with a $91.8 \%$ acceptance rate for pharmacist recommendations. In another study, a level 1 trauma center implemented an ASP pathway, wherein patients with MRSA bacteremia with elevated vancomycin MICs were switched from vancomycin to daptomycin based on approval by either an ID physician or a pharmacist. This study found that the ASP resulted in higher clinical success (75.0 vs. 41.4\%; $p<0.001$ ), lower nephrotoxicity (0 vs. $12.9 \%$ ), shorter length of stay (14 vs. 16 days; $p=0.04)$, reduction in duration of antibiotic therapy (9 vs. 13 days; $p=0.001$ ), and shorter duration of bacteremia ( 4 vs. 5 days; $p=0.004$ ) [62]. Finally, a retrospective study evaluated the effect of an ID pharmacist and ID physician ASP team on cost savings and patient care improvement in 2 large hospitals compared with hospitals within the same integrated system that had no ASP or an ASP with an ID physician only [63]. At 1 year after the implementation of the ASP team, use of anti-MRSA antimicrobials decreased by $9.9 \%$ and the comparator sites showed a $15 \%$ increase $(p<0.0001)$ in the same timeframe. Similarly, the cost of antimicrobials decreased (17.3\%), as did the hospital standardized mortality ratio for sepsis and respiratory infections for study hospitals. Taken together, these studies indicate that a successful pharmacist-directed ASP is associated with improved patient outcomes and represent a better use of pharmacist time than routine monitoring of vancomycin concentrations.

\section{Conclusions}

Sixty years after its introduction into clinical practice, vancomycin continues to have an important role in the treatment of severe Gram-positive infections. However, given the variable outcomes associated with vancomycin treatment, it remains critical to evaluate the key issues of drug toxicity, high trough concentrations, and the additional clinical time required to achieve effective treatment that can lead to this agent's diminished utility. Nephrotoxicity is the most significant adverse effect associated with vancomycin and is associated with increased length of stay, higher costs, use of alternative antibiotics, receipt of hemodialysis, and higher mortality rates. Monitoring vancomycin concentrations is recommended to optimize therapy, and, although there is a clear relationship between higher trough concentrations and the incidence of nephrotoxicity, a link between higher trough concentrations and efficacy is less clear. Monitoring vancomycin serum concentrations may not be cost effective for all patients. Significant resources are spent monitoring vancomycin concentrations that could be reallocated to ASPs, which have been shown to decrease antibiotic use, lower the incidence of nephrotoxicity, and promote better outcomes in patients.

\section{Compliance with Ethical Standards}

This manuscript has not been published elsewhere and is not under consideration by another journal. GPP3 and ICMJE criteria for authorship have been followed during manuscript development.

Funding Editorial support for preparing this review was provided by Tanmayi Mankame, PhD, of AlphaBioCom, LLC, and was funded by Theravance Biopharma Antibiotics, Inc.

Conflict of interest Meghan N. Jeffres had full control of the content and was not compensated for any activities. She owns stock in Pfizer and Merck.

Open Access This article is distributed under the terms of the Creative Commons Attribution-NonCommercial 4.0 International License (http://creativecommons.org/licenses/by-nc/4.0/), which permits any noncommercial use, distribution, and reproduction in any medium, provided you give appropriate credit to the original author(s) and the source, provide a link to the Creative Commons license, and indicate if changes were made.

\section{References}

1. Levine DP. Vancomycin: a history. Clin Infect Dis. 2006;42(Suppl 1):S5-12. doi:10.1086/491709.

2. Liu C, Bayer A, Cosgrove SE, Daum RS, Fridkin SK, Gorwitz $\mathrm{RJ}$, et al. Clinical practice guidelines by the infectious diseases society of America for the treatment of methicillin-resistant Staphylococcus aureus infections in adults and children. Clin Infect Dis. 2011;52(3):e18-55. doi:10.1093/cid/ciq146.

3. Rybak M, Lomaestro B, Rotschafer JC, Moellering R, Craig W, Billeter M, et al. Therapeutic monitoring of vancomycin in adult patients: a consensus review of the American Society of HealthSystem Pharmacists, the Infectious Diseases Society of America, and the Society of Infectious Diseases Pharmacists. Am J Health Syst Pharm. 2009;66(1):82-98. doi:10.2146/ajhp080434.

4. Rybak MJ, Lomaestro BM, Rotscahfer JC, Moellering RC, Craig WA, Billeter M, et al. Vancomycin therapeutic guidelines: a summary of Consensus Recommendations from the Infectious Diseases Society of America, the American Society of HealthSystem Pharmacists, and the Society of Infectious Diseases Pharmacists. Clin Infect Dis. 2009;49(3):325-7. doi:10.1086/ 600877.

5. Roberts JA, Taccone FS, Udy AA, Vincent J-L, Jacobs F, Lipman J. Vancomycin dosing in critically ill patients: robust methods for improved continuous-infusion regimens. Antimicrob Agents Chemother. 2011;55(6):2704-9. doi:10.1128/aac.01708-10.

6. Kullar R, Davis SL, Taylor TN, Kaye KS, Rybak MJ. Effects of targeting higher vancomycin trough levels on clinical outcomes and costs in a matched patient cohort. Pharmacotherapy. 2012;32(3):195-201. doi:10.1002/j.1875-9114.2011.01017.x. 
7. Pritchard L, Baker C, Leggett J, Sehdev P, Brown A, Bayley KB. Increasing vancomycin serum trough concentrations and incidence of nephrotoxicity. Am J Med. 2010;123(12):1143-9. doi:10.1016/j.amjmed.2010.07.025.

8. Bosso JA, Nappi J, Rudisill C, Wellein M, Bookstaver PB, Swindler J, et al. Relationship between vancomycin trough concentrations and nephrotoxicity: a prospective multicenter trial. Antimicrob Agents Chemother. 2011;55(12):5475-9. doi:10. 1128/aac.00168-11.

9. Holubar M, Meng L, Deresinski S. Bacteremia due to methicillinresistant Staphylococcus aureus: new therapeutic approaches. Infect Dis Clin N Am. 2016;30(2):491-507. doi:10.1016/j.idc. 2016.02.009.

10. Elting LS, Rubenstein EB, Kurtin D, Rolston KVI, Fangtang J, Martin CG, et al. Mississippi mud in the 1990s: risks and outcomes of vancomycin-associated toxicity in general oncology practice. Cancer. 1998;83(12):2597-607.

11. Van Hal S, Paterson D, Lodise T. Systematic review and metaanalysis of vancomycin-induced nephrotoxicity associated with dosing schedules that maintain troughs between 15 and 20 milligrams per liter. Antimicrob Agents Chemother. 2013;57(2):734-44.

12. Bellomo R, Ronco C, Kellum JA, Mehta RL, Palevsky P. Acute Dialysis Quality Initiative w. Acute renal failure-definition, outcome measures, animal models, fluid therapy and information technology needs: the Second International Consensus Conference of the Acute Dialysis Quality Initiative (ADQI) Group. Crit Care. 2004;8(4):R204-12. doi:10.1186/cc2872.

13. Naveen PSR. Definition of acute kidney injury. Int $\mathbf{J}$ Health Modern Integr Med Sci. 2014;1(1):10-4.

14. Mehta RL, Kellum JA, Shah SV, Molitoris BA, Ronco C, Warnock DG, et al. Acute kidney injury network: report of an initiative to improve outcomes in acute kidney injury. Crit Care. 2007;11(2):R31. doi:10.1186/cc5713.

15. Minejima E, Choi J, Beringer P, Lou M, Tse E, Wong-Beringer A. Applying new diagnostic criteria for acute kidney injury to facilitate early identification of nephrotoxicity in vancomycintreated patients. Antimicrob Agents Chemother. 2011;55(7):3278-83. doi:10.1128/aac.00173-11.

16. Prabaker KK, Tran TPH, Pratummas T, Goetz MB, Graber CJ. Elevated vancomycin trough is not associated with nephrotoxicity among inpatient veterans. J Hosp Med. 2012;7(2):91-7. doi:10. 1002/jhm.946.

17. Rello J, Nieto M, Sole-Violan J, Wan Y, Gao X, Solem CT, et al. Nosocomial pneumonia caused by methicillin-resistant Staphylococcus aureus treated with linezolid or vancomycin: a secondary analysis of resource use from a Spanish perspective. Med Intensiva. 2016;40(8):474-82.

18. Elyasi S, Khalili H, Dashti-Khavidaki S, Mohammadpour A. Vancomycin-induced nephrotoxicity: mechanism, incidence, risk factors and special populations. A literature review. Eur J Clin Pharmacol. 2012;68(9):1243-55. doi:10.1007/s00228-012-1259-9.

19. Wong-Beringer A, Joo J, Tse E, Beringer P. Vancomycin-associated nephrotoxicity: a critical appraisal of risk with high-dose therapy. Int J Antimicrob Agents. 2011;37(2):95-101. doi:10. 1016/j.ijantimicag.2010.10.013.

20. Hanrahan T, Whitehouse T, Lipman J, Roberts JA. Vancomycinassociated nephrotoxicity: a meta-analysis of administration by continuous versus intermittent infusion. Int J Antimicrob Agents. 2015;46(3):249-53. doi:10.1016/j.ijantimicag.2015.04.013.

21. Deresinski S. Vancomycin in combination with other antibiotics for the treatment of serious methicillin-resistant Staphylococcus aureus infections. Clin Infect Dis. 2009;49(7):1072-9. doi:10. 1086/605572.

22. Dilworth TJ, Ibrahim O, Hall P, Sliwinski J, Walraven C, Mercier RC. beta-Lactams enhance vancomycin activity against methicillin-resistant Staphylococcus aureus bacteremia compared to vancomycin alone. Antimicrob Agents Chemother. 2014;58(1):102-9. doi:10.1128/AAC.01204-13.

23. Gomes DM, Smotherman C, Birch A, Dupree L, Della Vecchia BJ, Kraemer DF, et al. Comparison of acute kidney injury during treatment with vancomycin in combination with piperacillin-tazobactam or cefepime. Pharmacotherapy. 2014;34(7):662-9. doi:10.1002/phar.1428.

24. Rutter WC, Burgess DR, Talbert JC, Burgess DS. Acute kidney injury in patients treated with vancomycin and piperacillin-tazobactam: a retrospective cohort analysis. J Hosp Med. 2017;12(2):77-82. doi:10.12788/jhm.2684.

25. Burgess LD, Drew RH. Comparison of the incidence of vancomycin-induced nephrotoxicity in hospitalized patients with and without concomitant piperacillin-tazobactam. Pharmacotherapy. 2014;34(7):670-6. doi:10.1002/phar.1442.

26. Lodise TP, Lomaestro B, Graves J, Drusano GL. Larger vancomycin doses (at least four grams per day) are associated with an increased incidence of nephrotoxicity. Antimicrob Agents Chemother. 2008;52(4):1330-6. doi:10.1128/aac.01602-07.

27. Hidayat LK, Hsu DI, Quist R, Shriner KA, Wong-Beringer A. High-dose vancomycin therapy for methicillin-resistant Staphylococcus aureus infections: efficacy and toxicity. Arch Intern Med. 2006;166(19):2138-44. doi:10.1001/archinte.166.19.2138.

28. Lodise TP, Patel N, Lomaestro BM, Rodvold KA, Drusano GL. Relationship between initial vancomycin concentration-time profile and nephrotoxicity among hospitalized patients. Clin Infect Dis. 2009;49(4):507-14. doi:10.1086/600884.

29. Kullar R, Davis SL, Levine DP, Rybak MJ. Impact of vancomycin exposure on outcomes in patients with methicillin-resistant Staphylococcus aureus bacteremia: support for consensus guidelines suggested targets. Clin Infect Dis. 2011;52(8):975-81. doi:10.1093/cid/cir124.

30. Cano EL, Haque NZ, Welch VL, Cely CM, Peyrani P, Scerpella $\mathrm{EG}$, et al. Incidence of nephrotoxicity and association with vancomycin use in intensive care unit patients with pneumonia: retrospective analysis of the IMPACT-HAP database. Clin Therap. 2012;34(1):149-57. doi:10.1016/j.clinthera.2011.12.013.

31. Jeffres MN, Isakow W, Doherty JA, Micek ST, Kollef MH. A retrospective analysis of possible renal toxicity associated with vancomycin in patients with health care-associated methicillinresistant Staphylococcus aureus pneumonia. Clin Therap. 2007;29(6):1107-15. doi:10.1016/j.clinthera.2007.06.014.

32. Shen WC, Chiang YC, Chen HY, Chen TH, Yu FL, Tang CH, et al. Nephrotoxicity of vancomycin in patients with methicillin-resistant Staphylococcus aureus bacteraemia. Nephrology (Carlton). 2011;16(8):697-703. doi:10.1111/j.1440-1797.2011.01488.x.

33. Hall RG, Giuliano CA, Haase KK, Hazlewood KA, Frei CR, Forcade NA, et al. Empiric guideline-recommended weight-based vancomycin dosing and mortality in methicillin-resistant Staphylococcus aureus bacteremia: a retrospective cohort study. BMC Infect Dis. 2012;12(104):1-5. doi:10.1186/1471-2334-12104.

34. Chertow GM, Burdick E, Honour M, Bonventre JV, Bates DW. Acute kidney injury, mortality, length of stay, and costs in hospitalized patients. J Am Soc Nephrol. 2005;16(11):3365-70. doi:10.1681/ASN.2004090740.

35. Tong MC, Wisniewski CS, Wolf B, Bosso JA. Comparison of linezolid and vancomycin for methicillin-resistant Staphylococcus aureus pneumonia: institutional implications. Pharmacotherapy. 2016;36(7):731-9. doi:10.1002/phar.1771.

36. Bamgbola $\mathrm{O}$. Review of vancomycin-induced renal toxicity: an update. Ther Adv Endocrinol Metab. 2016;7(3):136-47. doi:10. 1177/2042018816638223.

37. Davies SW, Guidry CA, Petroze RT, Hranjec T, Sawyer RG. Vancomycin and nephrotoxicity: just another myth? J Trauma 
Acute Care Surg. 2013;75(5):830-5. doi:10.1097/TA. 0b013e3182a74b70.

38. Wunderink RG, Niederman MS, Kollef MH, Shorr AF, Kunkel MJ, Baruch A, et al. Linezolid in methicillin-resistant Staphylococcus aureus nosocomial pneumonia: a randomized, controlled study. Clin Infect Dis. 2012;54(5):621-9. doi:10.1093/cid/cir895.

39. Niederman MS, Chastre J, Solem CT, Wan Y, Gao X, Myers DE, et al. Health economic evaluation of patients treated for nosocomial pneumonia caused by methicillin-resistant Staphylococcus aureus: secondary analysis of a multicenter randomized clinical trial of vancomycin and linezolid. Clin Ther. 2014;36(9):1233-1243.e1. doi:10.1016/j.clinthera.2014.06.029.

40. Baumann S. Supreme Court lets patent invalidation stand, generic Cubicin ${ }^{\circledR}$ could be coming. Wolters Kluwer. 6 June 2016. http:// health.wolterskluwerlb.com/2016/06/supreme-court-lets-patentinvalidation-stand-generic-cubicin-could-be-coming/. Accessed 27 Feb 2017.

41. Gauthier T. Antibiotic prices: forecasting in 2016. https://www. idstewardship.com/2016-trends-prescription-drug-expenditures/. Accessed 27 Feb 2017.

42. Helfand C. Zyvox. http://www.fiercepharma.com/special-report/ zyvox. Accessed 27 Feb 2017.

43. Kalil AC, Murthy MH, Hermsen ED, Neto FK, Sun J, Rupp ME. Linezolid versus vancomycin or teicoplanin for nosocomial pneumonia: a systematic review and meta-analysis. Crit Care Med. 2010;38(9):1802-8. doi:10.1097/CCM.0b013e3181eb3b96.

44. Patel N, Pai MP, Rodvold KA, Lomaestro B, Drusano GL, Lodise TP. Vancomycin: we can't get there from here. Clin Infect Dis. 2011;52(8):969-74. doi:10.1093/cid/cir078.

45. Parrillo J, Dellinger R. Critical care medicine: principles of diagnosis and management in the adult. Philadelphia: Elsevier/ Saunders; 2014.

46. Jeffres MN, Isakow W, Doherty JA, McKinnon PS, Ritchie DJ, Micek ST, et al. Predictors of mortality for methicillin-resistant Staphylococcus aureus health-care-associated pneumonia*: specific evaluation of vancomycin pharmacokinetic indices. Chest. 2006;130(4):947-55. doi:10.1378/chest.130.4.947.

47. Moise-Broder PA, Forrest A, Birmingham MC, Schentag JJ. Pharmacodynamics of vancomycin and other antimicrobials in patients with Staphylococcus aureus lower respiratory tract infections. Clin Pharmacokin. 2004;43(13):925-42.

48. Men P, Li HB, Zhai SD, Zhao RS. Association between the $\mathrm{AUC}_{0-24} / \mathrm{MIC}$ ratio of vancomycin and its clinical effectiveness: a systematic review and meta-analysis. PLoS One. 2016;11(1):e0146224. doi:10.1371/journal.pone.0146224.

49. Neely MN, Youn G, Jones B, Jelliffe RW, Drusano GL, Rodvold $\mathrm{KA}$, et al. Are vancomycin trough concentrations adequate for optimal dosing? Antimicrob Agents Chemother. 2014;58(1):309-16. doi:10.1128/aac.01653-13.

50. Holmes NE, Howden BP. What's new in the treatment of serious MRSA infection? Curr Opin Infect Dis. 2014;27(6):471-8. doi:10.1097/QCO.0000000000000101.

51. Walraven CJ, North MS, Marr-Lyon L, Deming P, Sakoulas G, Mercier RC. Site of infection rather than vancomycin MIC predicts vancomycin treatment failure in methicillin-resistant Staphylococcus aureus bacteraemia. $\mathrm{J}$ Antimicrob Chemother. 2011;66(10):2386-92. doi:10.1093/jac/dkr301.

52. Moise PA, Culshaw DL, Wong-Beringer A, Bensman J, Lamp $\mathrm{KC}$, Smith WJ, et al. Comparative effectiveness of vancomycin versus daptomycin for MRSA bacteremia with vancomycin MIC $>1 \mathrm{mg} / \mathrm{L}:$ a multicenter evaluation. Clin Therap. 2016;38(1):16-30. doi:10.1016/j.clinthera.2015.09.017.

53. Carreno JJ, Kenney RM, Divine G, Vazquez JA, Davis SL. Randomized controlled trial to determine the efficacy of early switch from vancomycin to vancomycin alternatives as a strategy to prevent nephrotoxicity in patients with multiple risk factors for adverse renal outcomes (STOP-NT). Annal Pharmacother. 2017;51(3):185-93. doi:10.1177/1060028016673858.

54. Darko W, Medicis JJ, Smith A, Guharoy R, Lehmann DF. Mississippi mud no more: cost-effectiveness of pharmacokinetic dosage adjustment of vancomycin to prevent nephrotoxicity. Pharmacotherapy. 2003;23(5):643-50. doi:10.1592/phco.23.5. 643.32199 .

55. Society for Healthcare Epidemiology of America, Infectious Diseases Society of America, Pediatric Infectious Diseases Society. Policy statement on antimicrobial stewardship by the Society for Healthcare Epidemiology of America (SHEA), the Infectious Diseases Society of America (IDSA), and the Pediatric Infectious Diseases Society (PIDS). Infect Control Hosp Epidemiol. 2012;33(4):322-7. doi:10.1086/665010.

56. Pakyz AL, Oinonen M, Polk RE. Relationship of carbapenem restriction in 22 university teaching hospitals to carbapenem use and carbapenem-resistant Pseudomonas aeruginosa. Antimicrob Agents Chemother. 2009;53(5):1983-6. doi:10.1128/AAC. 01535-08.

57. Lewis GJ, Fang X, Gooch M, Cook PP. Decreased resistance of Pseudomonas aeruginosa with restriction of ciprofloxacin in a large teaching hospital's intensive care and intermediate care units. Infect Control Hosp Epidemiol. 2012;33(4):368-73. doi:10. 1086/664763.

58. Buising KL, Thursky KA, Robertson MB, Black JF, Street AC, Richards MJ, et al. Electronic antibiotic stewardship-reduced consumption of broad-spectrum antibiotics using a computerized antimicrobial approval system in a hospital setting. J Antimicrob Chemother. 2008;62(3):608-16. doi:10.1093/jac/dkn218.

59. White AC Jr, Atmar RL, Wilson J, Cate TR, Stager CE, Greenberg SB. Effects of requiring prior authorization for selected antimicrobials: expenditures, susceptibilities, and clinical outcomes. Clin Infect Dis. 1997;25(2):230-9.

60. Fishman N. Policy Statement on Antimicrobial Stewardship by the Society for Healthcare Epidemiology of America (SHEA), the Infectious Diseases Society of America (IDSA), and the Pediatric Infectious Diseases Society (PIDS). Infect Control Hosp Epidemiol. 2012;33(04):322-7. doi:10.1086/665010.

61. Waters CD. Pharmacist-driven antimicrobial stewardship program in an institution without infectious diseases physician support. Am J Health Syst Pharm. 2015;72(6):466-8. doi:10. 2146/ajhp140381.

62. Kullar R, Davis SL, Kaye KS, Levine DP, Pogue JM, Rybak MJ. Implementation of an antimicrobial stewardship pathway with daptomycin for optimal treatment of methicillin-resistant Staphylococcus aureus bacteremia. Pharmacotherapy. 2013;33(1):3-10. doi:10.1002/phar.1220.

63. Fodero KE, Horey AL, Krajewski MP, Ruh CA, Sellick JA Jr, Mergenhagen KA. Impact of an antimicrobial stewardship program on patient safety in veterans prescribed vancomycin. Clin Therap. 2016;38(3):494-502. doi:10.1016/j.clinthera.2016.01. 001. 